\title{
Normal pressure hydrocephalus and the predictive value of presurgical tests
}

\author{
Hidrocefalia de pressão normal e o valor preditivo dos testes pré-cirúrgicos
}

Benito P. Damasceno'

1Universidade Estadual de
Campinas, Faculdade de Ciências
Médicas, Hospital das Clínicas,
Departamento de Neurologia,
Campinas SP, Brasil.
Correspondence:
Benito P. Damasceno;
Rua Ataliba Camargo de Andrade, 172;
13025-290 Campinas SP, Brasil;
E-mail: damascen@unicamp.br
Conflict of interest:
There is no conflict of interest to
declare.
Received 23 April 2018
Accepted 25 April 2018
(cc) BY

${ }^{1}$ Universidade Estadual de Campinas, Faculdade de Ciências ins, Hospital das Clínicas, Departamento de Neurologia,

Correspondence: Benito P. Damasceno; Rua Ataliba Camargo de Andr E-mail:damascen@unicamp.br Conflict of interest: declare.

(cc) BY

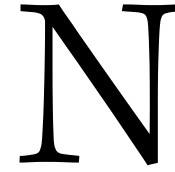

ormal pressure hydrocephalus (NPH) is characterized by gait disturbance, progressive mental deterioration and urinary incontinence associated with enlargement of the ventricular system and normal cerebrospinal fluid (CSF) pressure, although episodes of increased CSF pressure do occur. In NPH, the excessive accumulation of CSF in the ventricular system is due to an impairment of CSF flow distally to the fourth ventricle ("communicating"). About $50 \%$ of NPH cases are "secondary" (due to meningitis, subarachnoid hemorrhage, trauma) while the other $50 \%$ are "idiopathic" (iNPH), usually occurring in the $7^{\text {th }}$ decade of life. Normal pressure hydrocephalus is a rare cause of dementia (less than $5 \%$ of all demented patients), with iNPH showing an annual incidence between 1.8/100,000 and 5.5/100,000 inhabitants, and prevalence ranging from $0.2 \%$ to $2.9 \%$ among individuals aged 65 years or older, based on surveys in northern Europe and Japan.

Typical cases present with the triad of (1) gait disturbance as the first and most salient sign; followed by (2) an astheno-emotional syndrome characterized by difficulties in concentrating, increased irritability and fatigability, emotional instability, forgetfulness (more rarely, mild dementia), with psychomotor retardation, apathy, and sometimes a parkinsonian or depressive appearance; and, later on, (3) urinary urgency and/or incontinence. Gait disturbance is the cardinal sign in iNPH, typically a broad-based, short-step, slow magnetic gait with start hesitation and instability that is worst on turning, often with falls ${ }^{1}$. It is not a genuine gait apraxia, since the patient can execute the walking movements without difficulty when lying down, despite freezing their gait when standing on their feet and trying to initiate walking ${ }^{2}$. This gait impairment has been considered a gait ignition failure due to a frontal dysfunction or, more specifically, due to a frontal-basal ganglia disconnection, with uninhibited antigravity reflexes and co-contraction of agonists and antagonists during walking ${ }^{3}$. Most of the iNPH syndrome is explained by a reduction of blood flow and metabolism in the frontal lobes, basal ganglia, medial thalamus, hippocampus, and anterior parts of periventricular white matter 4

In the typical patients, the diagnosis is almost straightforward and, after shunting, they are the most likely to improve, mainly in their gait disturbance. However, particularly in cases with atypical or incomplete clinical manifestations, there may be differential diagnostic difficulties, as the triad can be mimicked by other conditions such as Parkinson's disease, progressive supranuclear palsy, and subcortical arteriosclerotic encephalopathy (Binswanger's disease), which are much more common than NPH. In the elderly, other more common conditions may also explain the gait difficulties (arthrosis or arthritis, peripheral neuropathy, vestibular disease), urinary incontinence (prostate disease, chronic urinary tract infection), and mental deterioration (Alzheimer's disease), particularly when the cognitive impairment predominates and precedes the motor and urinary disturbance. Thus, these diagnostic difficulties require more accurate methods and criteria for selection of patients for shunt surgery, which can benefit up to $80 \%$ of these patients but has up to $50 \%$ complication rates that dissuade us from shunting every case of suspected NPH. Among the diagnostic and prognostic supplementary tests, the most used are neuroimaging, intracranial pressure monitoring, the lumbar infusion test, and the CSF tap test.

Neuroimaging with computerized tomography or magnetic resonance imaging in iNPH show the following signs that are decisive for an NPH diagnosis and selection of shunt-responsive patients: ventricular enlargement out of proportion to the cerebral atrophy (with Evans index > 0.3), and associated ballooning of the frontal horns; periventricular hyperintensities; corpus callosum thinning and elevation, with a callosal angle between $40^{\circ}$ and $90^{\circ}$ (if greater than $90^{\circ}$, it suggests 
brain atrophy, as in Alzheimer's and Lewy body dementias); widening of the temporal horns not entirely explained by hippocampal atrophy; aqueductal or fourth ventricular flow void; enlarged Sylvian fissures and basal cistern, and narrowing of the sulci and subarachnoid spaces over the high convexity and midline surface of the brain ${ }^{5.6}$. On the other hand, other imaging methods such as radionuclide cisternography, singlephoton emission computed tomography, positron emission tomography, and even diffusion tensor imaging or resting-state functional magnetic resonance imaging, though compatible with an NPH diagnosis, as yet do not improve the accuracy of identifying shunt-responsive patients. A "positive" radionuclide cisternography may be seen in other dementias and even in healthy elderly subjects, and it has questionable predictive value.

Intracranial pressure monitoring usually shows peak elevations of CSF pressure (B waves), considered to predict a good postsurgical outcome, especially when they occur in more than $50 \%$ of the intracranial pressure recording time ${ }^{7}$.

In the lumbar infusion test, saline or artificial CSF infused into the ventricle or lumbar subarachnoid space raises the resistance to CSF outflow with subsequent increase of CSF pressure, which in NPH reaches higher levels than the plateau seen in normal individuals. A resistance to CSF outflow of $18 \mathrm{~mm}$ $\mathrm{Hg} / \mathrm{ml}$ per minute or higher ${ }^{8}$, and/or CSF pressure pulsatility ${ }^{9}$ are considered predictors of a good surgical outcome.

The CSF tap test consists of quantitative testing of gait and cognitive functions before and after the drainage of 30-50 ml lumbar CSF. It is the only test that can temporarily simulate the effect of an actual shunt, and is able to predict not only the outcome of surgery but also the degree of improvement. The one-tap CSF tap test has a high positive predictive value (up to 100\%) but low sensitivity (26-61\%), which can be improved by performing a repeated or continuous three-day external lumbar drainage (minimum of $150 \mathrm{ml}$ CSF drained daily), with high sensitivity (50-100\%) and high positive predictive value $(80-100 \%)^{10}$. In the European iNPH Multicentre Study the predictive values of the CSF tap test and lumbar infusion test in $115 \mathrm{iNPH}$ patients did not correlate with the outcome after 12 months (except for an increase in the gait task of the CSF tap test $)^{11}$.

In this issue of Arquivos de Neuro-Psiquiatria, Souza et al. ${ }^{12}$ present the results of a well-designed study of the effect of the CSF tap test on 15 gait variables of $25 \mathrm{NPH}$ patients, showing gait speed as the most responsive parameter, followed by cadence, step length, en bloc turning, and step height. Gait speed as the parameter with best response to CSF removal has already been established in the neurological literature. Further studies are needed to disclose postural and gait parameters, other than speed, that, isolated or combined, could best predict surgical results, by analyzing CSF tap test data of larger samples of patients who subsequently had good postsurgical outcomes, as the "gold standard" for iNPH diagnosis remains as the clinical improvement after CSF shunting.

Thus, the most relevant issue is whether or not the patient will benefit from shunt surgery. In this regard, the best predictors are a short disease duration, high cognitive scores (mild or no dementia), a gait disturbance preceding mental deterioration, typical neuroimaging findings, and a positive CSF tap test. Even though the most reliable prediction is achieved with a positive repeated or continuous CSF removal, a negative CSF tap test cannot be used to exclude patients from surgery, if the other predictors indicate a good outcome.

\section{References}

1. Damasceno BP. Normal pressure hydrocephalus: diagnostic and predictive evaluationon. Dement Neuropsychol. 2009 JanMar;3(1):8-15. https://doi.org/10.1590/S1980-57642009DN30100003

2. Estañol BV. Gait apraxia in communicating hydrocephalus. J Neurol Neurosurg Psychiatry. 1981 Apr;44(4):305-8. https://doi.org/10.1136/jnnp.44.4.305

3. Knutsson E, Lying-Tunell U. Gait apraxia in normal-pressure hydrocephalus: patterns of movement and muscle activation. Neurology. 1985 Feb;35(2):155-60. https://doi.org/10.1212/WNL.35.2.155

4. Owler BK, Momjian S, Czosnyka Z, Czosnyka M, Péna A, Harris NG et al. Normal pressure hydrocephalus and cerebral blood flow: a PET study of baseline values.J Cereb Blood Flow Metab. 2004 Jan;24(1):17-23. https://doi.org/10.1097/01.WCB.0000093326.88757.49

5. Mori E, Ishikawa M, Kato T, Kazui H, Miyake H, Miyajima M et al. Guidelines for management of idiopathic normal pressure hydrocephalus: second edition. Neurol Med Chir 2012;52(11):775-809. https://doi.org/10.2176/nmc.52.775

6. Damasceno BP. Neuroimaging in normal pressure hydrocephalus. Dement Neuropsychol. 2015 Oct-Dec;9(4):350-5. https://doi.org/10.1590/1980-57642015DN94000350

7. Larsson A, Stephensen H, Wikkelsö C. Normaltryckshydrocefalus: Demenstillstånd som förbättras med shuntkirurgi. Läkartidningen 1995;92(6):545-550.
8. Boon AJ, Tans JT, Delwel EJ, Egeler-Peerdeman SM, Hanlo PW, Wurzer HA et al. The Dutch normal-pressure hydrocephalus study. How to select patients for shunting? An analysis of four diagnostic criteria. Surg Neurol. 2000 Mar;53(3):201-7. https://doi.org/10.1016/S0090-3019(00)00182-8

9. Brean A, Eide PK. Prevalence of probable idiopathic normal pressure hydrocephalus in a Norwegian population. Acta Neurol Scand. 2008 Jul;118(1):48-53. https://doi.org/10.1111/j.1600-0404.2007.00982.x

10. Marmarou A, Bergsneider M, Klinge P, Relkin N, Black $\mathrm{PM}$. The value of supplemental prognostic tests for the preoperative assessment of idiopathic normal-pressure hydrocephalus. Neurosurgery. 2005 Sep;57(3 Suppl):S17-28. https://doi.org/10.1227/01.NEU.0000168184.01002.60

11. Wikkels $\varnothing$ C, Hellström P, Klinge PM, Tans JT; European iNPH Multicentre Study Group. The European iNPH Multicentre Study on the predictive values of resistance to CSF outflow and the CSF Tap Test in patients with idiopathic normal pressure hydrocephalus. J Neurol Neurosurg Psychiatry. 2013 May;84(5):562-8. https://doi.org/10.1136/jnnp-2012-303314

12. Souza RKM, Rocha SFB, Martins RT, Kowacs PA, Ramina R. Gait in normal pressure hydrocephalus: characteristics and effects of the CSF tap test. Arq Neuropsiquiatr. 2018;76(5):324-31. https://doi.org/10.1590/0004-282X20180037 